\title{
The venous footpump: influence on tissue perfusion and prevention of venous thrombosis
}

\author{
A M N Gardner, R H Fox
}

Development of the technique of video phlebography has enabled the anatomy and physiology of the venous pump in the human foot to be demonstrated. ${ }^{1}$ This hitherto largely unrecognised organ consists of the abnormally large venae comites of the lateral plantar artery (fig 1). The plantar venous pump has a stroke volume of between 20 and $30 \mathrm{ml}$ and is activated simply by weight bearing.

There are three misconceptions relating to the venous return from the foot which have been disproved by video phlebography. (a) The concept of a peripheral venous pump has always embraced the idea of active muscular contraction; however, video phlebography shows that this is not true in the foot. Passive weight bearing flattens the plantar arch, stretching the veins longitudinally, causing them to constrict 'neck down' and dislocate the blood with sufficient force to overcome the resistance of

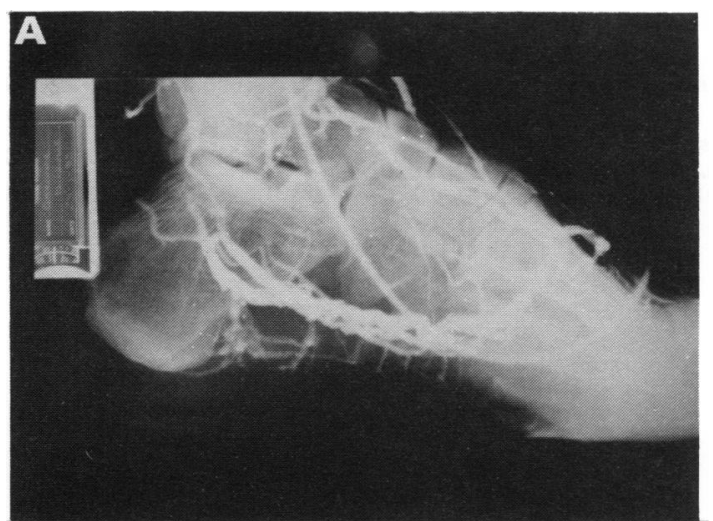

Torbay Hospital, Torbay, Devon, United Kingdom

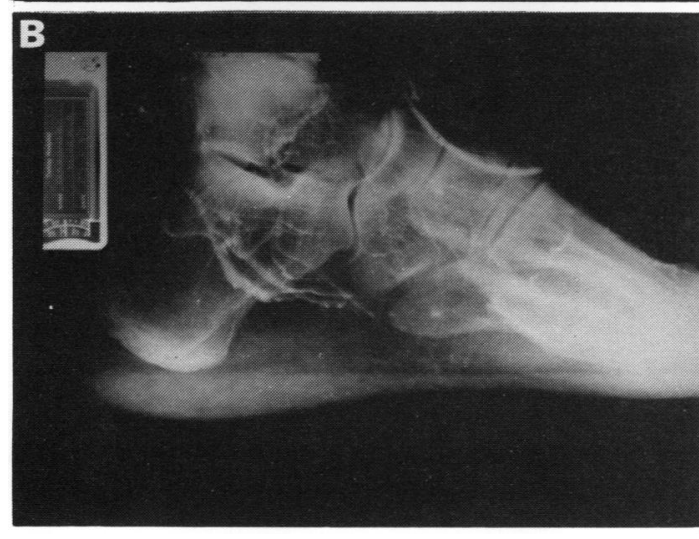

a sphygmomanometer cuff inflated to over $100 \mathrm{~mm}$ around the calf. This alone is adequate to return blood from the foot to the right atrium in the upright position. The foot pump has been shown to be functional in paraplegic legs. ${ }^{2}$ The blood returns in a jerky fashion with the venous valves acting as haemodynamic ratchets. ${ }^{23}$ (b) The belief that the plantar veins drain onto the dorsum of the foot is a second fallacy; video phlebography shows that the blood is pumped

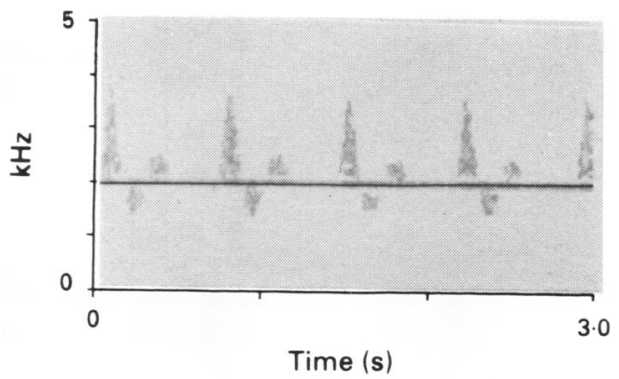

Erect non-weight bearing

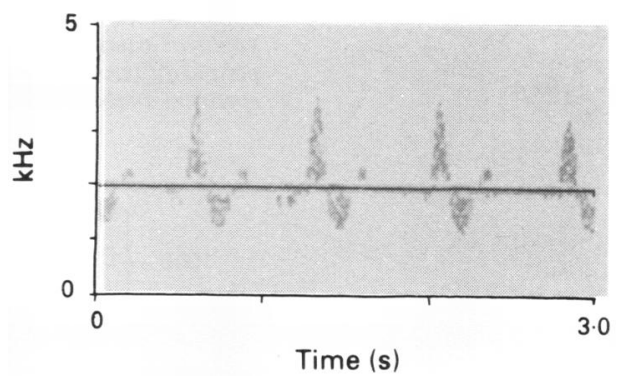

Erect weight bearing

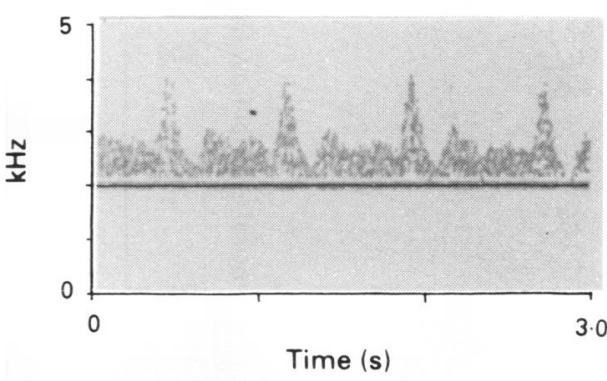

Erect after weight bearing

Figure 1 Phlebogram of the foot of one of the authors (AMNG). The venous foot pump consists mainly of the enlarged venae comites of the lateral plantar artery. (A) Nonweight bearing, ankle movement had no effect, dorsiflexion of the toes merely emptied the small precalcaneal plexus of veins. (B) Weight bearing emptied the venous foot pump up

Figure 2 Original Doppler flow recording of posterior tibia arterial flow at the ankle $(R H F)$, which showed the phenomenon of postcompression hyperaemia. (Top) Erect non-weight bearing. (Middle) Erect weight bearing, note slight decrease in forvard flow and increase in reverse flow. (Bottom) Erect after lifting foot from the ground. There was a large and persistent increase in forward flow of over $100 \%$ and an absence of reversed flow. ATL Doppler recording at Cardiff. 
preferentially up into the deep channels of the calf. $^{2}$ (c) A third misconception is that blood from the subcutaneous plantar venous plexus (the semelle veineux plantaire of Winkler ${ }^{4}$ ) is sucked into the deep veins of the foot by spreading of the metatarsals; such aspiration is impossible because the veins would simply collapse.

The importance of normal venous return in resolving disease and injury of the lower limb has prompted the development of a pneumatic device that activates the venous foot pump in a physiological manner and reduces the risk of venous thrombosis without resorting to treatment with anticoagulant drugs. The implications are therefore profound in the field of rheumatology and orthopaedics. The device is described at the end of this review.

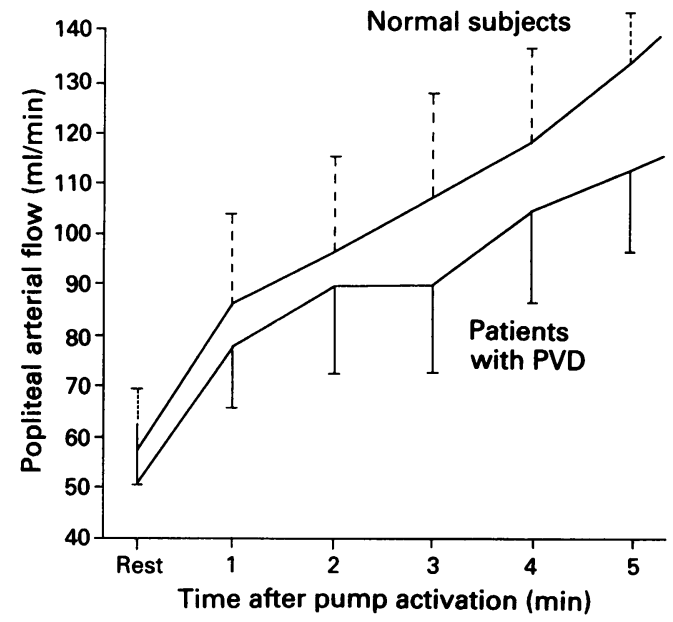

Figure 3 Intermittent pneumatic compression increases popliteal arterial flow in normal subjects and in patients with peripheral vascular disease (PVD). ATL Doppler plus spectrum analyser.
In common with other veins in the leg the foot veins are prone to thrombosis in association with thrombosis higher in the limb and in isolation, where it can account for some cases of 'plantar fasciitis'. In subjects with march haemoglobinuria the plantar veins are the probable site of haemolysis. ${ }^{2}$ There is a similar mechanism of venous return in the arm and this is mirrored in other species.

\section{Blood flow and tissue perfusion}

Haemodynamic studies of blood flow induced in the posterior tibial vessels at the ankle by weight bearing have shown that blood flow increases immediately after the foot is unloaded. Doppler tracing (fig 2) showed that the increase in total blood flow far exceeded the decrease in flow which occurred during weight bearing. This observation was followed by a series of experiments by Morgan et al using a pneumatic impulse device to activate the foot pump in 10 patients with vascular disease and 12 normal subjects. ${ }^{5}$ The observed hyperaemia caused by the device was an increase in popliteal blood flow of $93 \%(\mathrm{p}<0.0001)$ in normal subjects and $84 \%(\mathrm{p}<0.03 \%)$ in patients (fig 3). A placebo device produced no significant change in flow. Activation of the foot pump did not alter the blood pressure but each impulse decreased the peripheral vascular resistance and increased blood flow for about 25 seconds. This still occurred in ischaemic limbs with arterial obstruction. The observations were made in the foot down position as the hyperaemic effect was dependent on venous priming (fig 4).

Increased arterial flow following compression has been observed for over a century, initially in the foot web of frogs ${ }^{6}$ and latterly in human legs using xenon-133. ${ }^{7}$ The hyperaemia has until recently been assumed to be due to an increase
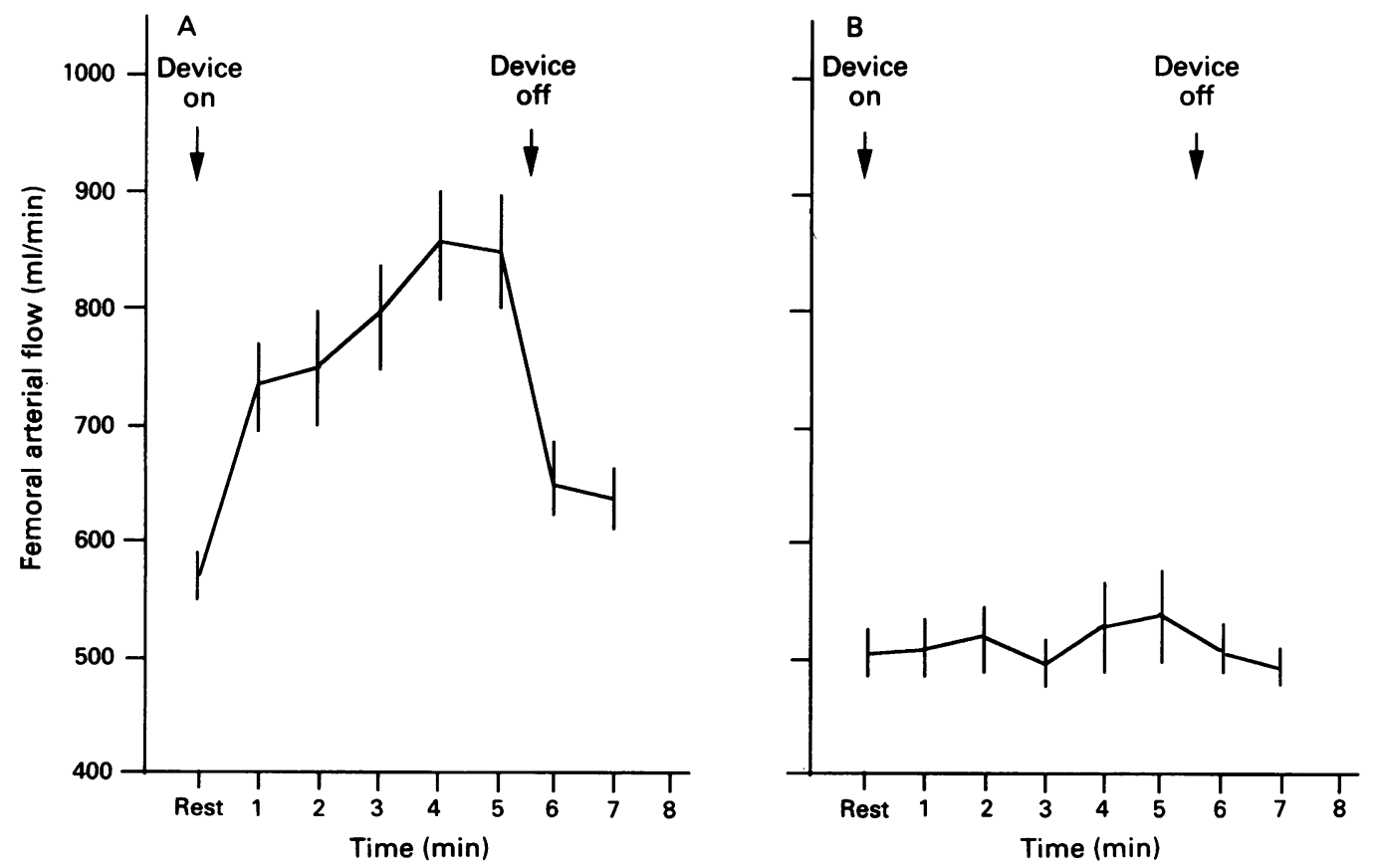

Figure 4 Effect of impulse pumping on common femoral arterial flow in a patient with a femoropopliteal arterial block. (A) Sitting leg at $45^{\circ}$. (B) Same patient lying supine. The hyperaemic effect of impulse compression is dependent on venous priming. 
in the arteriovenous pressure gradient following expulsion of venous blood from the limb. This concept of microcirculatory blood flow is no longer valid. Arterial inflow and venous outflow are separated by a capillary bed that consists of collapsible tubes, with only about one in six usually being open at one time. ${ }^{8}$ The model of high pressure at one end of a capillary forcing venous blood out of the other would only be tenable if the capillaries were rigid tubes or collapsible tubes held fully open, in which instance Poiseuille's law would apply. ${ }^{9}$

Hyperaemia following impulse compression is not confined to the tissues of the foot within the cuff as popliteal blood flow may be doubled. Indeed under some circumstances increased arterial flow may start during the compression phase (fig 5). The increase appears to be triggered by the pulsation imparted to venous return flow by activation of each cycle of the foot pump. This finding is in keeping with the experiments of Lewis and Grant, who in 1925 showed hyperaemia following transient venous occlusion. ${ }^{10}$ More recent studies of tissue perfusion have shown that the rapid increase in perfusion pressure is mainly responsible for the temporary decrease in peripheral vascular resistance. ${ }^{11} 12$

Until recently there has been no satisfactory explanation for these observations. Retrograde opening up of the microcirculation was postulated and reversed capillary flow had been observed by Florey, ${ }^{13}$ but it was unclear, even if
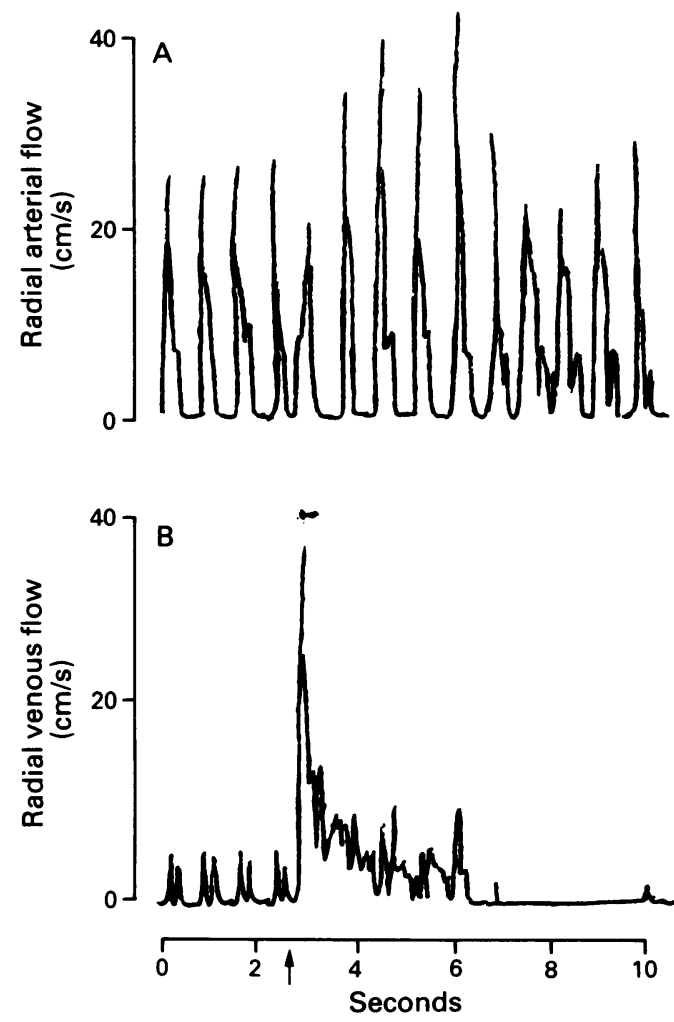

Figure 5 In some circumstances hyperaemia may start during the three second compression period. Impulse pumping applied in a glove to the hand. Doppler records of radial arterial flow $(A)$ and synchronous radial venous flow (B) after hand cooling in a patient with mild Raynaud's disease. Arrow shows start of three second compression period. Percompression hyperaemia is potentiated by a period of venous congestion. this was induced, how it could influence the precapillary sphincters that are the main determinants of capillary flow.

The discovery of endothelial cell derivatives which can constrict or dilate vessels ${ }^{14}$ has been pivotal to our understanding of the control of the microcirculation and it is now possible to construct a modified view of Starling's concept of tissue nutrition (fig 6). Most important is endothelial relaxing factor (EDRF), which was discovered in $1984^{15}$ and is now known to be nitric oxide with a half life of between six and 50 seconds. ${ }^{16}$

Endothelial relaxing factor mediates the relaxation of arteriolar smooth muscle by various endogenous hormones including acetylcholine. Its production in endothelium is stimulated by the 'shear stress' caused by sudden pressure change. It is thus a tissue hormone (autocoid): it diffuses locally where its action is confined to the tissues where it is generated and it is rapidly neutralised by plasma, haemoglobin and myoglobin in the presence of oxygen. ${ }^{17-20}$ The short half life of EDRF corresponds well with the short duration of postimpulse compression hyperaemia (approximately 20 seconds $^{2}$ ). Endothelial relaxing factor is continually being produced because if neutralised by its antagonist L-arginine, blood pressure increases greatly. ${ }^{21}$ It is therefore an important element in the control of systemic vascular resistance and hence blood pressure, and is counterbalanced by the inherent contraction of vascular smooth muscle that occurs in response to stretch (Bayliss phenomenon). ${ }^{22}$ Significantly EDRF has been found to be deficient in patients with hypertension. ${ }^{21}$

The previously unexplained mechanisms whereby tissue blood flow is matched to the oxygen requirement may be explained by the prolongation of the life of the tissue hormone (autocoid) EDRF in anoxia. ${ }^{20}$ Likewise EDRF can explain how blood flow in skeletal muscle is rapidly increased following contraction. ${ }^{11} 2324$ Muscle contraction produces a sudden increase in blood pressure in the intramuscular venules; the resultant shear stress causes the endothelium to produce EDRF that rapidly diffuses from the venules to the closely adjacent arterioles (Windkessel vessels), causing them to dilate. ${ }^{19} 25$ In support of this concept are the observations that venous congestion increases postcontraction hyperaemia ${ }^{26}$ and exercise tolerance, ${ }^{27} 28$ whereas in the reverse situation when the veins are empty hyperaemia and capacity for muscular exercise are reduced, as anyone working above their head will confirm. Prostacyclin-like EDRF is produced by shear stress and its longer half life (four minutes) may account for the more persistent component of impulse compression hyperaemia.

Another autocoid produced by endothelial shear stress is the peptide endothelial derived constricting factor (EDCF) that apparently has the opposite effect to EDRF on vascular smooth muscle. The physiological role of EDCF has not been defined; in low concentrations it is a vasodilator and its vasoconstrictor effect is more marked in veins than arteries (Vane J, personal communication). As it is a larger molecule than 


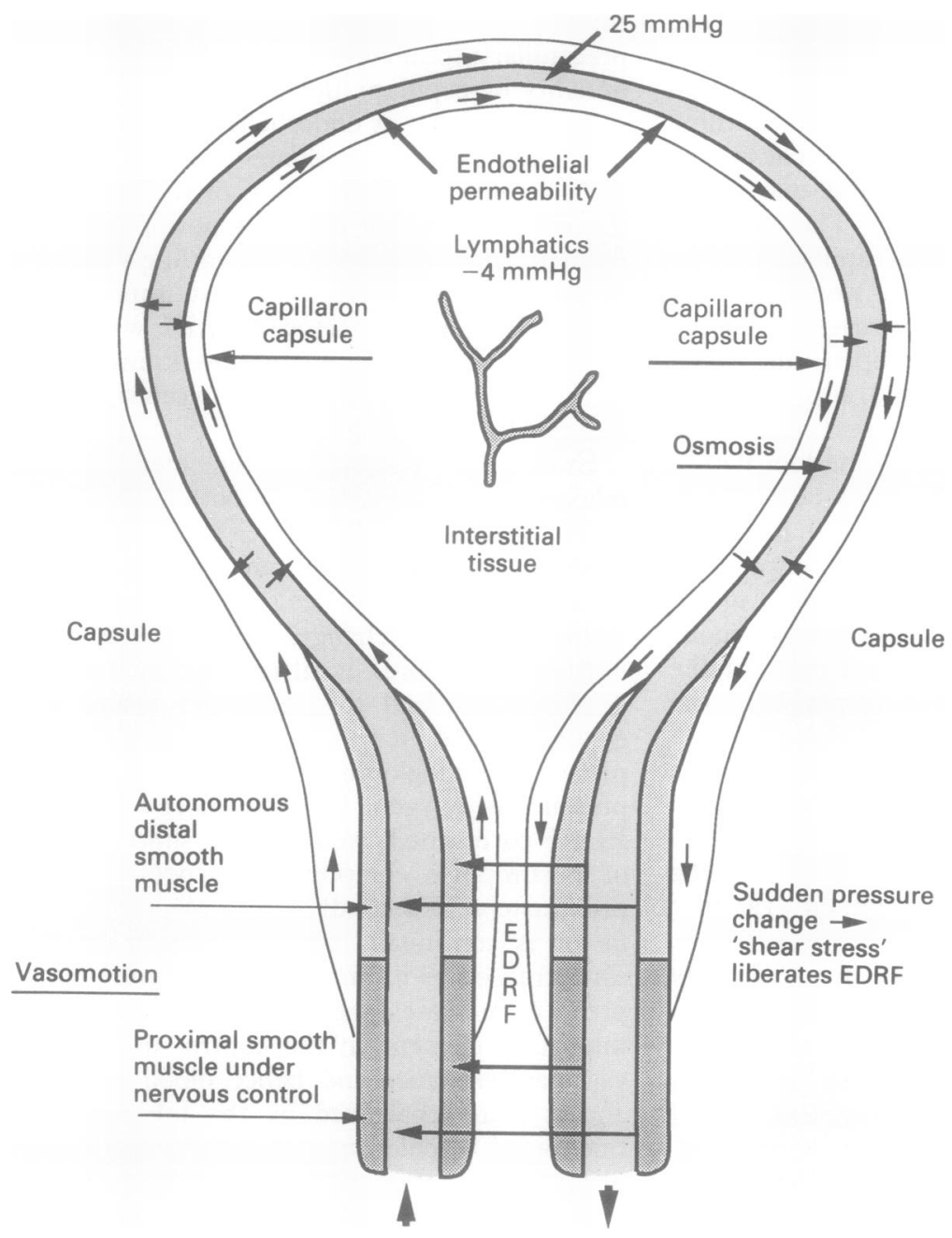

Figure 6 Starling's diagram of the capillary loop. Suggested modification according to recent advances in the understanding of the microcirculation. Distal arteriolar flow control is by a balance of vasoconstriction in response to increased pressure (Bayliss response) and dilatation by endothelial relaxing factor $(E D R F)$ (nitric oxide) produced by endothelium in response to sudden pressure change. Intrinsic rhythm of arteriolar muscle (vasomotion) causes capillaries intermittently to open and close. Pericapillary fluid circulation through Capillaron capsule is indicated by fluorescin capillaroscopy; note difference in capillary and lymphatic pressures. Endothelial permeability plays a vital part in regulation of tissue fluid and nourishment. paedic and neurosurgery. The most dangerous thromboses are those in the femoropopliteal and larger veins, emboli from which may be fatal. Least dangerous are emboli from the muscle sinuses which give rise to emboli that are small enough to be lysed within the lung with no late sequelae. ${ }^{2}$ Thromboses in the main venous channels commonly lead to the postphlebitic syndrome and chronic ulcers; these are the result of chronic venous hypertension caused by obstruction to flow and valve damage that impairs the function of venous pumps. In the long term (four to five years) fibrin accumulates around the capillaries ${ }^{29} 30$ leading to nutritional changes in skin and other tissues: vein walls become weakened and often become varicose. ${ }^{2}$

The association between skeletal injury and venous thrombosis is well known and may influence the decision to submit patients for joint replacement. The incidence of major proximal deep vein thrombosis after hip operations without anticoagulant drugs is around $50 \% .^{31-33}$ A related problem is the delayed development of postphlebitic problems in about half the patients after tibial fracture (table). ${ }^{34}$

Physical prophylaxis for venous thrombosis after an operation avoids the complications of pharmacological methods and if effective is clearly more desirable. It is to this end that several centres around the United Kingdom have taken part in controlled trials of pneumatic impulse pumping of the foot and the prophylactic effect is now proved (fig 7). ${ }^{35}$

The mechanisms whereby impulse pumping prevents thrombosis are thought to be: $(a)$ the turbulence, seen on video phlebography, which is induced in valve pockets where thrombosis commonly begins; $(b)$ release of EDRF, which not only produces hyperaemia but also inhibits and even reverses platelet aggregation ${ }^{36} 37$; (c) release of prostacyclin ${ }^{38}$; and $(d)$ enhancement of fibrinolysis after tissue compression. ${ }^{39-43}$

If impulse pumping is used in established thrombosis there is the theoretical risk of triggering pulmonary embolism. Emboli so dislodged are small and clinically insignificant and the risk is certainly less than that of ambulation where contraction of the thigh muscles risks dislodgement of thrombi large enough to block pulmonary circulation.

It is easy to see how a systemic constricting action limited to the venous system could be important in controlling blood volume distribution in shock and stress, but more importantly could be a local action constricting venular smooth muscle, causing capillary congestion, decreasing the capillary arteriovenous pressure gradient, increasing EDRF production, and improving tissue nutrition. Such an action might be most important in contragravitational areas of the circulation, particularly the brain. Support for this hypothesis is the histological finding of an increase of smooth muscle in cerebral venules.

\section{Venous thrombosis in the legs}

The importance of the unsolved problem of thromboembolism cannot be overemphasised; anticoagulant drugs save lives but bleeding problems limit their use, particularly in ortho-

Effects of impulse compression on compartmental pressures in 11 patients with severe tibial fractures. In three patients an increase in pressure occurred when pumping was discontinued. Two patients were considered to be saved from fasciotomy

\begin{tabular}{lll}
\hline Effect & $\begin{array}{l}\text { Pressure } \\
\text { change } \\
\text { (mmHg) }\end{array}$ & $\begin{array}{l}\text { Time needed for change } \\
\text { (hours })\end{array}$ \\
\hline
\end{tabular}

\begin{tabular}{lcc}
\hline Decreased from & & \\
$>40 \mathrm{mmHg}(\mathrm{n}=4)$ & $40-10$ & 34 \\
& $45-36$ & 7 \\
& $47-36$ & 9 \\
& $49-32$ & 2 \\
Decreased $(\mathrm{n}=2)$ & $31-27$ & 26 \\
& $38-27$ & 3 \\
Increased $(\mathrm{n}=1)$ & $10-14$ & 1 \\
Unchanged $(\mathrm{n}=4)$ & 9 & \\
& 27 & 24 Hours after treatment \\
& 28 & Tense haemarthrosis; \\
& 65 & fasciotomy after 30 minute:
\end{tabular}




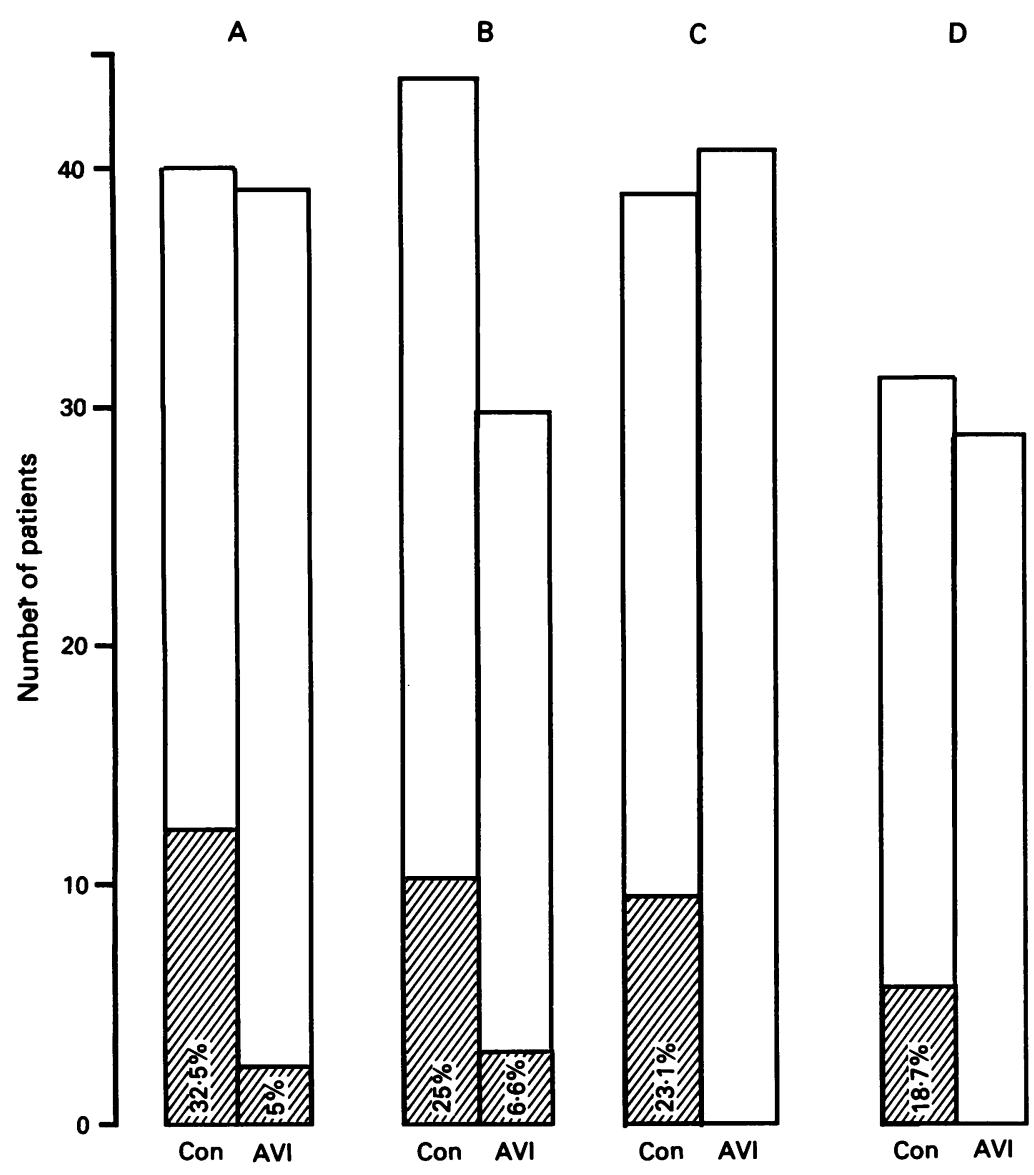

Figure 7 Effect of impulse pumping in reducing risk of major thrombosis (shaded areas of columns) after operations on hips and knees. Con =control; $A V I=$ patients treated by pneumatic impulse pumping. (A) Exeter. Total hip replacement, phlebographic study. (B) Scarborough. Total hip replacement, phlebographic study. (C) Portsmouth. Neck of femur after fracture, Doppler study. (D) King's College Hospital (London). Total knee replacement, phlebographic study. Results of $A, B$, and $C$ were statistically significant with respect to femoropopliteal thrombosis and $D$ likewise when distal thromboses were included.

Impulse pumping has been used successfully in conjunction with streptokinase in threatened venous gangrene (A M N Gardner, unpublished observations).

Pneumatic impulse activation of the venous foot pump: A-V impulse system

The impulse compression device (fig 8) differs

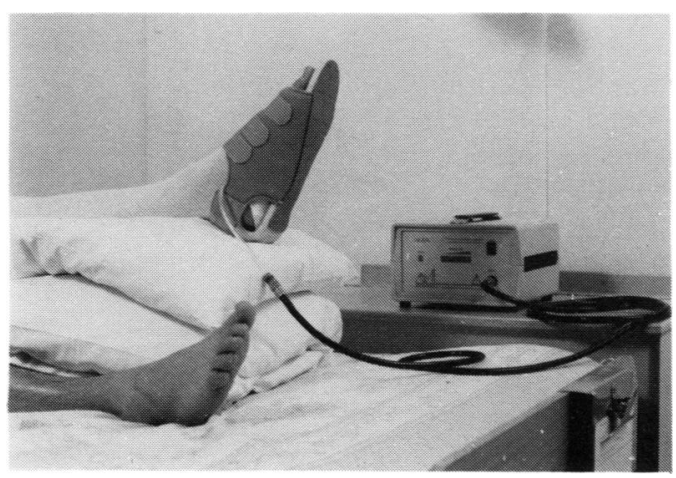

Figure 8 AVI device. The main body of the machine contains an electrical compressor, an air reservoir, valves, and timing mechanism that intermittently and rapidly inflates a cuff applied around the foot. To be effective the venous

footpump must be primed, so a graduated stocking is worm on the calf and the leg positioned below heart level. This system is manufactured and supplied by Novamedix Lid, Viscount Court, South Way, Walworth, Andover, Hampshire SP10 $5 N W$, United Kingdom.

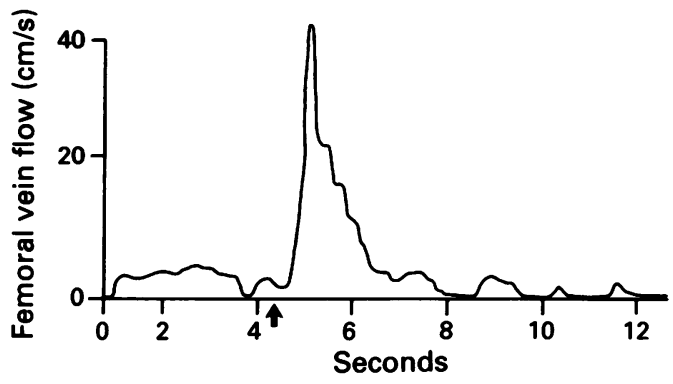

Figure 9 Femoral vein flow using the device with a leg in a plaster cast (tracing of Sonicaid Vasoflow 2 recording).

from all previous compression devices in that it is applied only to the mid foot and inflates rapidly, thus mimicking the haemodynamic action of normal ambulation. It consists of a pneumatic cuff wrapped around the foot and worn beneath a purpose made slipper. It can also fit within a plaster cast and can be applied to the hand when an appropriately shaped inflation pad is confined within a glove. Inflation is rapid ( $<0.4$ seconds) and intermittent (20 second cycle), metered from an air reservoir and compressor. This rapid inflation imitates the effect of normal gait by generating vigorous haemodynamic impulses throughout the venous conduits (fig 9$)^{2}$ in addition to turbulence in the valve pockets where many major thromboses originate. In clinical practice the hyperaemic effect of impulse compression has proved useful. In a controlled study it has been shown to increase blood flow and to alleviate rest pain in ischaemic limbs ${ }^{2}$ and may also limit tissue necrosis in patients with arterial insufficiency during investigations while waiting for an operation. ${ }^{5}$ Similarly, a significant reduction of these two parameters occurs with impulse compression in patients with limb pain and swelling after trauma. ${ }^{44}$

The beneficial effect of impulse compression on pain and swelling after trauma has been proved. ${ }^{43}$ This may be due in part to the liberation of EDRF which itself has an analgesic effect, ${ }^{45}$ but more importantly may be the clearance of kinins from tissues and reduction of venous congestion with neutralisation of the resulting acidosis that probably increases sensitivity to pain. ${ }^{46}$ In compartmental syndromes impulse compression of the foot can often reduce dangerously high pressures thereby allowing capillaries to reopen and thus avoid the need for fasciotomy (table). ${ }^{44}$ Studies are in progress to determine whether impulse compression can improve bone healing; accelerated recovery from fractures of the os calcis has been shown. ${ }^{47}$ Also encouraging are initial experiences in treating algodystrophy and facilitating physiotherapy.

As it has been suggested that rheumatoid arthritis may be an example of reperfusion injury with hypoxia, ${ }^{48}$ it is possible that alteration of blood flow could influence the pathological process within the joint. As blood flow can be improved in ischaemic limbs it is not beyond the realms of possibility that joint perfusion kinetics could be similarly manipulated. 
1 Gardner A M N, Fox R $H$. The venous pump of the human foot. Bristol Medico-chirurgical fournal 1983; 98: 109-12. 2 Gardner A M N, Fox R H. The return of blood to the heart. London: Libbey, 1989

3 Gardner A M N, Fox R H. The return of blood to the hear against the force of gravity. In: Negus D, Jantet G, eds. Phlebology '85. London: Libbey, 1986: 68-71.

4 Winkler G. Les veines du pied. Archives of Anatomy (Strasbourg) 1923; 37: 175-84.

5 Morgan R H, Carolan G, Psaila J V, Gardner A M N, Fox $R$ H, Woodcock J P. Arterial flow enhancement by impulse compression. Vasc Surg 1991; 25: 8-16.

6 Roy C S, Brown J G. The blood pressure and its variations in the arterioles, capillaries and smaller veins. $\mathcal{f}$ Physiol 1879 ; 2: 329-59.

7 Gaskell P, Parrot J C W. The effect of a mechanical venous pump on the circulation of the feet in arterial obstruction. Surg Gynecol Obstet 1978; 146: 583-92.

8 Krogh A. Anatomy and physiology of capillaries. New York: Yale University Press, 1929.

9 Whittaker S R F, Winton F R. The apparent viscosity of blood flowing in the isolated hind limb of the dog. $\mathcal{F}$ Physio (Lond) 1933; 339-69.

10 Lewis T, Grant R. Observations on reactive hyperaemia in man. Heart 1925; 12: 73-120.

11 Mohrman D E, Sparks H V. Myogenic hyperemia following brief tetanus of canine skeletal muscle. Am F Physiol 1974 227: $531-5$.

12 Smiesko V. Unidirectional rate sensitivity component in local control of vascular tone. Pflugers Arch 1971; 327: 324-36.

13 Florey $\mathbf{H}$. Microscopic observations on the circulation of the blood in the cerebral cortex. Brain 1925; 48: 43-64.

14 Anonymous. Endothelins [leading article]. Lancet 1991; i: $79-81$.

15 Furchgott R F, Zawadski J V. The obligatory role of endothelial cells in the relaxation of arterial smooth muscl by acetylcholine. Nature 1984; 288: 373-6.

16 Palmer R M J, Ferrige A G, Moncada S. Nitric oxide releas accounts for the biological activity of endothelium-derived relaxing factor. Nature 1987; 327: $524-6$.

17 Anonymous. Yin and yang in vasomotor control [leading articlel. Lancet 1988; ii: 19-20.

18 Anonymous. EDRF [leading article]. Lancet 1987; ii: 137-8.

19 Ignarro L J, Byrns R E, Buga G M Wood K S. Endotheliumderived relaxing factor from pulmonary artery and vein possesses pharmacological and chemical properties identical to those of nitric oxide radical. Circ Res 1987; 61: 866-79.

20 Fairchild H M, Ross J, Guyton A C. Failure of recovery from Fairchild $\mathrm{H} M$, Ross J, Guyton A C. Failure of recovery from
reactive hyperemia in the absence of oxygen. Am $\mathcal{F}$ P hysiol 1966; 210: 490-2.

21 Vallance P, Collier J, Moncada S. Effects of endotheliumderived nitric oxide on peripheral arteriolar tone in man Lancet 1989; ii: 997-1000.

22 Bayliss W M. On the local reactions of the arterial wall to changes of internal pressure. $\mathcal{f}$ Physiol (Lond) 1902; 28 : 228-31.

23 Anrep G V, Blalock A, Samaan A. The effect of muscular contraction upon the blood flow in the skeletal muscle. Proc $R$ Soc Lond [Biol] 1934; 114: 223-45.

24 Barcroft $\mathrm{H}$, Millen J L E. The blood flow through muscle during sustained contraction. 7 Physiol (Lond) 1939; 97: $17-31$.

25 Zweifach B W, Mety D B. Selective distribution of blood through the terminal vascular bed-mesenteric and skeletal. Angiology 1955; 6: 282-90.

26 Folkow B U, Haglund U, Jodal M, Lundgren O. Blood flow in the calf muscle of man during heavy rhythmic exercise. Acta Physiol Scand 1971; 81: 157-63.
27 Rodbard S, Farbstein $M$. Improved exercise tolerance during venous congestion. I Appl Physiol 1972; 33: 704-10.

28 Rodbard S, Deliry J L, Jaffe P. Venous pressure and exercise tolerance. Cardiology 1976; 61: 229-31.

29 Burnand K G, Clemenson G. The effect of sustained venous hypertension on the skin capillaries of the canine hind limb. Br. J Surg 1982; 69: 41-4.

30 Burnand $\mathrm{K} \mathrm{G}$, Whimster I. Pericapillary fibrin in the ulcer bearing skin of the leg the cause of lipodermatosclerosis. BMF 1982; 285: 1071-2.

31 Ishak M A, Morley D. Deep venous thrombosis after total hip arthroplasty. Br $\mathcal{F}$ Surg 1981; 68: 429-32.

32 Stamatakis J D, Kakkar V V. Femoral vein thrombosis and total hip replacement. $B M \mathcal{F}$ 1977; ii: $223-5$.

33 Lassen M R, Boris L C. Prevention of thromboembolism in 190 hip arthroplasties. Comparison of low molecular weight 34 Aitken R J, Mills C, Immelman E J. The postphlebitic syndrome following tibial shaft fracture. $\mathcal{J}$ Bone Joint Surg [Br] 1987; 69: 775-8

35 Fordyce $M$ J F, Ling R S M. The prevention of DVT following hip replacement by use of the A-V Impulse system. I Bone foint Surg [Br] 1992; 74: 45-9.

36 Griffith T M, Henderson A $H$. EDRF and the regulation of vascular tone. Int 7 Microcirc Clin Exp 1989; 8: 383-96.

37 Griffith T M. Endothelium-influenced vasomotion: models and measurements. In: Westerhof $\mathrm{N}$, Gross D R, eds. and measurements. In: Westerhof $\mathrm{N}$, Gross $\mathrm{D}$ R, eds. Vascular dynamics-physiological perspectives. Ne
Plenum Press, 1989: 177-93 (Nato ISA Series).

38 Guyton D P, Khyat A, Husni E A, Schreiber H. Elevated levels of 6-keto-prostaglandin-Fla from a lower extremity during external pneumatic compression. Surg Gynecol Obste 1988; 166: 338-42.

39 Allenby F, Pflug J J, Boardman L, Calnan J S. Effects of external pneumatic compression on fibrinolysis in man. Lancet 1973; ii: 1412-4.

40 Knight $M$, Dawson $R$, Ackerley $R$, Jones L. Intermitten compression of the arms reduces the incidence of postoperative venous thrombosis in the legs: an explanation. Lance ????; ii: 1265-8.

41 Tarnay T J, Rohr P R. Pneumatic calf compression, fibrinolysis and the prevention of deep venous thrombosis. Surgery 1980; 88: 489-96.

42 Altenkamper $\mathbf{H}$. Intluence d'une compression intermittente sur l'activitie fibrinolytique de la paroi veineuse chez des sur lactivitie fibrinolytique de la paroi veineuse chez des
patients souffrant de maladie variqueuse. In: Davy A, Stemmer R, eds. Phlebologie '89, Vol. 2. London: Libbey, 1989: 855 .

43 Hull R D, Rascob G E. Prophylaxis of venous thromboembolic disease following hip and knee surgery. $\mathcal{F}$ Bon foint Surg $[A \mathrm{Am}]$ 1986; 68: 146-50.

44 Gardner A M N, Fox R H, Lawrence C, Bunker T D, Ling R S M, MacEachern A G. Reduction of post-traumatic swelling and compartment pressure by impulse compression of the foot. F Bone foint Surg [Br] 1990; 72: 810-5.

45 Griffith T M, Randall M. Nitric oxide comes of age. Lancet 1989; ii: $875-6$.

46 Lindahal O. Experimental skin pain. Acta Physiol Scand 1961; 51 (suppl 179): 1-89.

47 Erdmann $M$ W H, Richardson J, Templeton j. Ös calcis fractures: a randomised trial of conservative treatment versus impulse compression of the foot. Injury 1992; 23 versus 305 .

48 Stevens C R, Williams R B, Farrell A J, Blake D R. Hypoxi and inflammatory synovitis: observations and speculation Ann Rheum Dis 1991; 50: 124-32. 